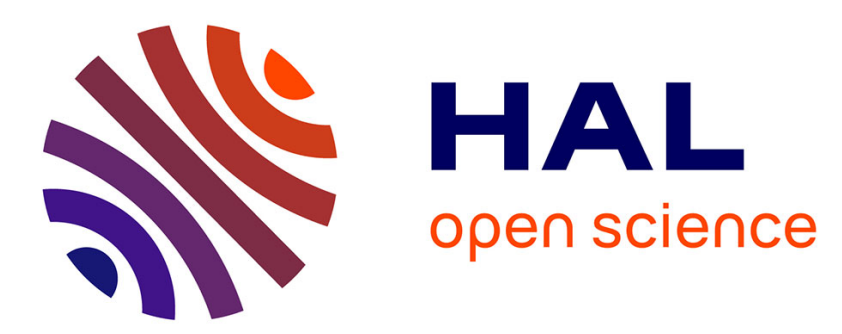

\title{
Electronic conduction and breakdown in non-polar liquids
}

W.F. Schmidt

\section{To cite this version:}

W.F. Schmidt. Electronic conduction and breakdown in non-polar liquids. Revue de Physique Appliquée, 1987, 22 (9), pp.1113-1116. 10.1051/rphysap:019870022090111300 . jpa-00245651

\section{HAL Id: jpa-00245651 https://hal.science/jpa-00245651}

Submitted on 1 Jan 1987

HAL is a multi-disciplinary open access archive for the deposit and dissemination of scientific research documents, whether they are published or not. The documents may come from teaching and research institutions in France or abroad, or from public or private research centers.
L'archive ouverte pluridisciplinaire HAL, est destinée au dépôt et à la diffusion de documents scientifiques de niveau recherche, publiés ou non, émanant des établissements d'enseignement et de recherche français ou étrangers, des laboratoires publics ou privés. 
Classification

Physics Abstracts

$52.80-72.80-82.50$

\title{
Electronic conduction and breakdown in non-polar liquids
}

\author{
W. F. Schmidt \\ Hahn-Meitner-Institut Berlin, Bereich Strahlenchemie, 1000 Berlin 39, F.R.G.
}

(Reçu le 22 décembre 1986, accepté le 5 mars 1987)

Résumé. - Il est donné une brève revue de la dynamique et du comportement énergétique des électrons en excès dans les liquides non polaires.

Abstract. - A brief review is given of the energetics and dynamics of electronic conduction processes in nonpolar liquids.

\section{Introduction.}

Electrical conduction of non-polar liquids has been investigated to a great extent since the beginning of this century. This interest was mainly spurred by the use of mineral oil as insulant in various apparatus of high voltage technology. Nowadays, advanced electrotechnical systems (superconducting magnets, coaxial discharge lines with liquid spark gaps, cryogenic cables, etc.) or the use of liquid ionization chambers in radiation physics have shifted the focus to the investigation of conduction processes in ultrapure liquids where the predominant charge carriers are electrons and holes or positive ions. A considerable amount of data has been accumulated during the last 15 years and a deeper understanding of the participation of electronic charge carriers in the electrical conduction of non-polar liquids is emerging. Further research in this field will definitely lead to new applications. Here a brief overview of the energetics and dynamics of electronic charge carriers in ultrapure liquefied rare gases, hydrocarbons and derivatives is given.

\section{Electrons and holes in non-polar liquids.}

2.1 General Remarks. - Non-polar liquids are in the pure state very good insulators with large ionization potentials of the molecules or atoms comprising the liquid. Thermal generation of parent charge carriers at room temperature is negligible. Generation of charge carriers may proceed under the influence of a high electric field, for instance at the electrodes, or under the action of energetic radiation. Electrons and holes are chemically very reactive species. Electrons readily attach to electronegative impurities while holes transfer their charge to impurities with a smaller ionization energy. The electron attachment process has been investigated to a great detail and rate constants $k_{\mathrm{s}}$ for the process

$$
\mathrm{e}^{-}+\mathrm{S} \underset{k_{\mathrm{s}}}{\rightarrow} \mathrm{S}
$$

have been measured for a number of electron attaching compounds in several non-polar liquids [1]. The rate constant depends on the type of solute $S$ and on the liquid, but typically values between $10^{10}$ and $10^{14} 1 \mathrm{~mole}^{-1} \mathrm{~s}^{-1}$ have been measured. The life time $\tau$ of electrons with respect to attachment is then defined as

$$
\tau=\frac{1}{k_{\mathrm{s}}[S]}
$$

where $[S]$ denotes the concentration of $S$ in moles/litre. At a concentration of $1 \mu$ mole/litre the electron life time becomes

$$
\tau=10^{-4} \mathrm{~s} \text { for } k_{\mathrm{s}}=10^{10}
$$

and

$$
\tau=10^{-8} \mathrm{~s} \text { for } k_{\mathrm{s}}=10^{14} .
$$

These times give the boundary conditions under which a certain experiment on electronic conduction has to be carried out. It was found that the reaction rate constant is influenced by the presence of an external electric field $[2,3]$.

The observation of holes is more difficult. Their observation has been reported so far for a few 
liquids only. Fragmentation of the parent ion, dimer formation or charge transfer to impurities may limit the life time of a hole depending on the type of liquid. While the first two processes occur so fast that their observation may not be possible, charge transfer has been observed in cyclohexane and rate constants in the range of $10^{11} \mathrm{l} / \mathrm{mole} / \mathrm{s}$ have been found for transfer to other hydrocarbons. Purification of a particular liquid hydrocarbon to a level of $1 \mu \mathrm{mole} / \mathrm{l}$ with respect to other hydrocarbons is very difficult because highly fractionated destillation or gaschromatography seem to be the only methods available. These methods are very time consuming and they allow the purification of small samples only. Since in the starting material other hydrocarbons are present at a high concentration ( 0.1 to 1 vol. \%) it is extremely difficult to obtain the required low impurity concentration.

2.2 MobiLiTy. - One of the fundamental quantities describing the transport of charge carriers in a nonpolar liquid under the influence of an electric field is the drift mobility. The methods used for the measurement of the electron mobility have been reviewed repeatedly $[4,5]$ so that we will discuss here the results only.

2.2.1 Electrons. - Effect of structure. One of the interesting features of electron mobility in non-polar liquids is the large variation with molecular structure. In table I some examples are given for liquid hydrocarbons and liquefied rare gases. Although a comparison of the mobility data at one specific temperature or of those obtained at different tem- peratures incorporates a certain ambiguity, some general properties can be extracted by inspection of table I. In normal alkanes a decrease of the electron mobility at room temperature with increasing chain length is observed. For $n>7$ ( $n$-heptane) the mobility seems to level off. This indicates that the mode of electron transport in these liquids is similar. Branching leads to higher values of the mobility with liquids that contain a quarternary atom exhibiting the highest values (e. g. neopentane, tetramethylsilane).

Effect of temperature. Electron mobilities in liquid hydrocarbons generally exhibit positive temperature coefficients. Exceptions are high mobility liquids as for instance methane, where a strong variation of the mobility with temperature was found in the vicinity of the critical temperature. Most normal alkanes show over a limited temperature range an Arrhenius type dependence with activation energies around 0.1 to $0.2 \mathrm{eV}$.

Effect of an electric field. At low electric field strength strict proportionality between drift velocity and field strength is observed. The mobility obtained is referred to as low field mobility. At higher field strength deviations from this proportionality are observed in such a way that in liquids and at temperatures where the mobility is $>10 \mathrm{~cm}^{2} \mathrm{~V}^{-1} \mathrm{~s}^{-1}$ a sublinear dependence of $v_{\mathrm{d}}$ on $F$ is observed while in liquids and at temperatures where the mobility is $<1 \mathrm{~cm}^{2} \mathrm{~V}^{-1} \mathrm{~s}^{-1}$ a superlinear dependence is being seen.

Measurements of the electron mobility in liquid ethane as a function of temperature and electric field strength showed transition from a super-linear de-

Table I. - Electron mobilities in non-polar liquids (from ref. [1]).

\begin{tabular}{l|l|c|c}
\hline \multicolumn{1}{c|}{ Liquid } & \multicolumn{1}{c|}{ Chemical Symbol } & $T[K]$ & $\left(\mathrm{cm} \mathrm{V}^{-1} \mathrm{~s}^{-1}\right)$ \\
\hline Xenon & $\mathrm{Xe}$ & 161 & 1900 \\
Krypton & $\mathrm{Kr}$ & 115 & 1800 \\
Argon & $\mathrm{Ar}$ & 85 & 475 \\
Neon & $\mathrm{Ne}$ & 25 & $1.6 \times 10^{-2}$ \\
Helium & ${ }^{4} \mathrm{He}$ & 4.2 & $2 \times 10^{-2}$ \\
Methane & $\mathrm{CH}_{4}$ & 111 & 400 \\
Ethane & $\mathrm{C}_{2} \mathrm{H}_{6}$ & 111 & $1.3 \times 10^{-3}$ \\
$n$-Butane & $\mathrm{C}_{4} \mathrm{H}_{10}$ & 296 & 0.34 \\
$n$-Pentane & $\mathrm{C}_{5} \mathrm{H}_{12}$ & 296 & 0.15 \\
$n$-Hexane & $\mathrm{C}_{6} \mathrm{H}_{14}$ & 296 & 0.09 \\
$n$-Octane & $\mathrm{C}_{8} \mathrm{H}_{18}$ & 296 & 0.04 \\
$n$-Decane & $\mathrm{C}_{10} \mathrm{H}_{22}$ & 296 & 0.038 \\
Neopentane & $\mathrm{C}_{2}\left(\mathrm{CH}_{3}\right)_{4}$ & 296 & 70 \\
Neohexane & $\left.\mathrm{CH}_{3} \mathrm{C}_{4} \mathrm{CH}_{3}\right)_{2} \mathrm{C}_{2} \mathrm{H}_{5}$ & 296 & 12 \\
Isooctane & $\mathrm{CH}_{3}$ & 296 & 7 \\
Tetramethyl silane & $\mathrm{CH}_{3} \mathrm{CH}_{2} \mathrm{CH}_{2} \mathrm{CH}\left(\mathrm{CH}_{3}\right)_{2}$ & & \\
\hline & $\mathrm{CH}_{3}$ & 296 & 90 \\
\hline
\end{tabular}




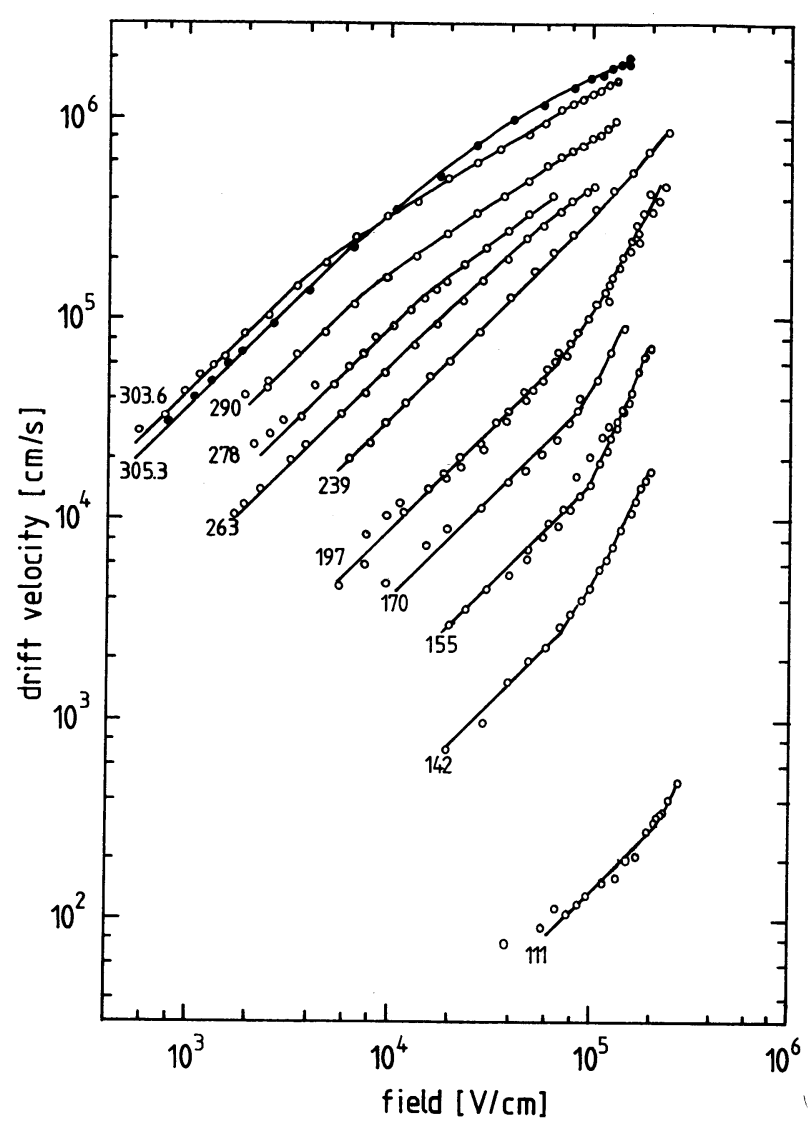

Fig. 1. - Dependence of the electron drift velocity in liquid ethane on the electric field strength and on the temperature (after: W. Döldissen, W. F. Schmidt and G. Bakale, J. Phys. Chem. 84 (1980) 1179.

pendence of the drift velocity on the electric field strength to a sub-linear dependence for temperature exceeding $0^{\circ} \mathrm{C}$ (Fig. 1).

2.2.2 Holes. - Evidence for fast positive charge carriers in some liquid hydrocarbons was first obtained from steady state and pulse radiolysis studies. The preparation of extremely pure samples allowed the direct observation of hole transport in cyclohexane, methyl-cyclohexane and trans-decalin [6-8]. The data obtained are summarized in table II. The hole transport is little influenced by variation of temperature and if at all there seems to be a slight decrease of the mobility with increasing temperature.

\section{Electronic Energy Levels.}

The fundamental quantities which governs thermal generation of charge carriers in non-polar liquids is the ionization energy. In comparison with the gas phase ionization potential $I_{\text {gas }}$ of the atoms or molecules comprising the liquid, a-reduction takes place in the liquid phase due to three effects: a) polarization by the positive ion $\left(P_{+}\right)$, b) electron affinity of the liquid $\left(V_{0}\right)$, and c) broadening of the valence levels $\left(E_{\mathrm{val}}\right)$

$$
I_{\text {liq }}=I_{\text {gas }}+P_{+}+V_{0}+E_{\text {val }} .
$$

While $P_{+}$and $E_{\text {val }}$ are negative, $V_{0}$ may be either positive or negative. Except for LHe, $\mid P_{+}+$ $E_{\text {val }}|>| V_{0} \mid$ has been found and the ionization energy $I_{\text {liq }} \leqslant I_{\text {gas }} \cdot I_{\text {liq }}$ can be determined by photo conductivity measurements with vacuum UV light. A compilation of values is given in table III.

The electron affinity of the liquid, $V_{0}$, which is also known as the energy of the bottom of the conduction band can be determined by comparing the photo electric threshold of a metal cathode in vacuum and in the liquid. A compilation of relevant data is given in table IV.

\section{Electronic Breakdown.}

Evidence for the important role of electronic processes in the development of an electric breakdown was obtained so far in the liquefied rare gases (LXe and LAr) and in some cryogenic molecular liquids $\left(\mathrm{LN}_{2}, \mathrm{LH}_{2}, \mathrm{LO}_{2}\right)$. Townsend type electron avalanches were observed in LXe under the condition of a strongly inhomogeneous electric field where the anode was a wire or a tip [9, 10].

LXe and LAr are particularly favorable liquids for this type of experiment. They do not exhibit vibrational levels and the first excited electronic state is only a few eV below the ionization energy. Furthermore, the low field electron mobility is large indicating a weak interaction of the electron with the medium. Energy from the field can be converted into kinetic energy of random electron motion. The only energy sink available is the first excited state. Once this energy is reached by the electrons there will be enough electrons of higher energy in the tail

Table II. - Hole mobilities $\mu \cdot 10^{3} \mathrm{~cm}^{2} \mathrm{~V}^{-1} \mathrm{~s}^{-1}$ as a function of temperature (after ref. [6-8], and J. Warman, private communication, 1978).

\begin{tabular}{|c|c|c|c|c|c|c|c|c|c|c|}
\hline \multirow[t]{2}{*}{ Liquid } & \multicolumn{10}{|c|}{ Temperature $t^{\circ} \mathrm{C}$} \\
\hline & -26 & -15 & 2 & 19 & 22 & 38 & 56 & 78 & 82 & 108 \\
\hline Cyclohexane & & & & 10.5 & & 8.4 & 9.0 & 9.7 & & \\
\hline Methylcyclohexane & & & & & 5.8 & & & & & \\
\hline Trans decalin & 14.4 & 8.2 & 10.2 & & 9.0 & 8.8 & 7.2 & & 7.9 & 7.7 \\
\hline
\end{tabular}


Table III. - Ionization energies of non-polar liquids (after ref. [5]).

\begin{tabular}{lcc}
\hline \multicolumn{1}{c}{ Liquid } & $T[K]$ & $I_{\text {liq }}(\mathrm{eV})$ \\
\hline Xenon & 161 & 9.2 \\
Krypton & 121 & 11.55 \\
Tetramethylsilane & 294 & $8.1 \pm 0.05$ \\
& & $8.05 \pm 0.05$ \\
Tetramethylgermanin & 294 & $7.6 \pm 0.05$ \\
Tetramethyltin & 294 & $6.9 \pm 0.1$ \\
Neopentane & 294 & $8.85 \pm 0.1$ \\
& & $8.55 \pm 0.05$ \\
Isopentane & 294 & $9.15 \pm 0.05$ \\
$n$-pentane & 294 & $9.15 \pm 0.1$ \\
& & $8.86 \pm 0.05$ \\
Neohexane & 294 & $8.73 \pm 0.05$ \\
& & $8.49 \pm 0.05$ \\
$n$-hexane & 294 & $8.59 \pm 0.05$ \\
3-methylpentane & 294 & $8.85 \pm 0.1$ \\
Isooctane & 294 & $8.3 \pm 0.05$ \\
$n$-tridecane & 294 & $9.25 \pm 0.05$ \\
$n$-pentene-1 & 294 & $8.33 \pm 0.05$ \\
Cyclopentene & 294 & $7.4 \pm 0.05$ \\
Cyclopentane & 294 & $8.8 \pm 0.05$ \\
Cyclohexane & 294 & $8.75 \pm 0.1$ \\
& & $8.43 \pm 0.05$ \\
Tetramethylethylene & 294 & $6.80 \pm 0.05$ \\
Hexamethyldisilane & 294 & $6.75 \pm 0.1$ \\
Triethylsilane & 294 & $8.25 \pm 0.1$ \\
\hline
\end{tabular}

of the energy distribution, making collisional ionization possible.

In a parallel plate arrangement this development would immediately switch over to a streamer leading to complete breakdown of the gap.
Table IV. $-V_{0}$-Values for non-polar liquids (after ref. [5]).

\begin{tabular}{l|c|c}
\hline \multicolumn{1}{c|}{ Liquid } & $T[K]$ & $V_{0}(\mathrm{eV})$ \\
\hline Helium & 4.2 & +1.05 \\
Neon & 25 & +0.67 \\
Argon & 84 & -0.2 \\
Krypton & 116 & -0.40 \\
Xenon & 161 & -0.67 \\
Methane & 100 & -0.25 \\
Ethane & 100 & +0.2 \\
$n$-pentane & 296 & 0.0 \\
$n$-hexane & 296 & +0.04 \\
Neopentane & 296 & -0.43 \\
Neohexane & 296 & -0.15 \\
Isooctane & 296 & -0.18 \\
Tetramethylsilane & 296 & -0.62 \\
\hline
\end{tabular}

In molecular liquids, energy sinks of much lower energy are available. Vibrational levels are the order of $0.1 \mathrm{eV}$. The first excited electronic levels are in the range of a few $\mathrm{eV}$ while the ionization energies lies between 8 and $10 \mathrm{eV}$. It may be assumed that the excitation of vibrations leads at once to heating of the liquid along the path of the electrons and a vapor channel is formed in which the discharge proceeds $[11,12]$.

\section{Conclusion.}

The study of electronic conduction processes has just begun. Many more problems wait to be solved. It can be predicted that with the advancement of our knowledge ultrapure non-polar liquids will find unique applications in experimental physics and electro-technology.

\section{References}

[1] SCHMidT, W. F., « Electron migration in liquids and glasses", chapter 7 in : Electron-solvent and anion-solvent interactions, L. Kevan and B. C. Webster eds. (Elsevier Publ. Co., Amsterdam) 1976.

[2] Bakale, G., Sowada, U. and Schmidt, W. F., J. Phys. Chem. 80 (1976) 2556.

[3] Bakale, G. and Schmidt, W. F., Z. Naturforsch. 36a (1981) 862.

[4] SCHMidT, W. F., chapter 9 in Photoconductivity and related phenomena, J. Mort and D. M. Pai Eds. (Elsevier Publ. Co., Amsterdam) 1976.

[5] SCHMIDT, W. F., IEEE Trans. EI-19 (1984) 389.

[6] De haAs, M. P., Warman, J. M. and Hummel, A.,
Proc. 5.ICDL (Delft University Press) 1975.

[7] De HaAs, M. P., Warman, J. M. Infelta, P. P. and Hummel, A., Chem. Phys. Lett. 31 (1975) 382.

[8] De HaAs, M. P., Hummel, A., Infelta, P. P. and Warman, J. M., J. Chem. Phys. 65 (1976) 5019.

[9] Derenzo, S. E., Mast, T. S., ZaKlaD, H. and Muller, R. A., Phys. Rev. A 9 (1974) 2582.

[10] Yoshino, K., SowAdA, U. and Schmidt, W. F., Trans. IEE Jpn, A 46 (1977) 355.

[11] Fuhr, J., Schmidt, W. F. and SAto, S., J. Appl. Phys. 59 (1986) 3694.

[12] Fuhr, J. and Schmidt, W. F., J. Appl. Phys. 59 (1986) 3702. 